\title{
PERCEPÇÕES DE LICENCIANDOS SOBRE ASPECTOS TECNOLÓGICOS, PEDAGÓGICOS E DE CONTEÚDO NO ENSINO DE FÍSICA: DESAFIOS PARA A FORMAÇÃO DOCENTE
}

\author{
RAMON TEODORO DO PRADO \\ Instituto Federal do Espírito Santo (Ifes) \\ E-mail: ramontp05@gmail.com \\ ROSILAINE DE FÁTIMA WARDENSKI \\ Universidade Federal do Rio de Janeiro \\ E-mail: rosiwardenski@gmail.com

\section{LAÍS GONÇALVES BERRUEZO} \\ Universidade Federal do Rio de Janeiro \\ E-mail: lais_berruezo@hotmail.com

\section{TAÍS RABETTI GIANNELLA} \\ Universidade Federal do Rio de Janeiro \\ E-mail: taisrg@yahoo.com.br
}

\section{RESUMO}

Este artigo analisa as percepções de licenciandos de física sobre aspectos tecnológicos, pedagógicos e de conteúdo, de maneira a contribuir para a pesquisa e a prática da formação docente. Trata-se de uma pesquisa qualitativa na qual foram realizadas entrevistas com 12 alunos finalistas da licenciatura em física de um Instituto Federal, cujos resultados foram abordados com base na análise temática de conteúdo. Os resultados apontaram para três conjuntos de percepções: 1) sobre a profissão docente e o papel do professor, indicando visões simplificadas sobre as habilidades necessárias para a prática docente; 2) sobre o ensino de física, indicando que deveria estar relacionado ao cotidiano e evitar a matematização de conceitos físicos em demasia e 3) sobre a integração de tecnologias educacionais, evidenciando poucas perspectivas de integração tecnológica situada. Esses resultados reforçam a necessidade de facilitar a construção e a integração entre conhecimentos tecnológicos, pedagógicos e de conteúdo (TPACK) no âmbito da formação docente.

\section{PalaVRas-ChaVE:}

Ensino de física; Formação inicial de professores; Tecnologias na educação. 
ABSTRACT

This paper analyses physic pre-service teachers' perceptions about technological, pedagogical and content aspects, aiming at contribute to research. It was realized interviews with 12 last year students from a graduating course for physic teacher education, analysed based on thematic content analysis. This is a qualitative research whose results point to three sets of perceptions: 1) about teaching profession and teacher's role, indicating simplified visions about the necessary skills for teaching practice; 2) about physic teaching, indicating that it should be related to everyday life and avoid using math too much and; 3) about educational technologies integration, evidencing little situated integration perspectives. These results reinforce the need to support the technological, pedagogical content knowledges (TPACK) formation and integration in teacher education.

\section{KEYWORDS:}

Physics teaching; Pre-service teaching education; Technologies in education.

\section{INTRODUÇÃO}

Este trabalho contém elementos apresentados em uma tese de doutorado cuja proposta desenvolve e analisa os resultados de um curso de formação de professores voltado para o uso de tecnologias digitais, de maneira articulada aos aspectos pedagógicos e de conteúdo, no contexto da licenciatura em física.

Um ponto comum defendido por diferentes pesquisadores é o fato de que a prática docente é uma atividade complexa, dinâmica e interdisciplinar (MISHRA, KOEHLER, 2006; 2008; NIESS, 2005; JOOGT, MCKENNEY, 2017; SANTOS, SANTOS, 2017) a qual demanda, processos formativos que proporcionem vivências de experimentação e reflexão, possibilitando um desenvolvimento profissional seguro (ROSA et al, 2017).

Esse desenvolvimento requer diferentes tipos de saberes (JOOGT, MCKENNEY, 2017) e, considerando a ampla difusão dos recursos tecnológicos em nossa sociedade (ALMEIDA; VALENTE, 2016), podemos destacar a importância da integração as tecnologias digitais de informação e comunicação (TDIC) em contextos educacionais. Para apoiar a construção de tais conhecimentos, nos apoiaremos na abordagem do TPACK (Conhecimento Tecnológico Pedagógico de Conteúdo, da sigla em inglês, Technological Pedagogical Content Knowledge), que tem como base os estudos de 
Shulman (1986) e propõe os conhecimentos necessários à formação docente para a inserção de recursos tecnológicos em sala de aula (NAKASHIMA, PICONEZ, 2016). Para alguns autores, o TPACK configura-se como uma estrutura conceitual útil para explicar o tipo de conhecimento que os professores precisam para integrar a tecnologia no ensino (JOOGT, MCKENNEY, 2017; SCHMIDT et al, 2009). A abordagem TPACK pode ser adotada na formação de professores para auxiliar a compreender como os sujeitos desenvolvem os conhecimentos necessários à docência, potencializando sua formação e as experiências de desenvolvimento profissional (SCHMIDT et al, 2009).

No ensino de física especificamente, diversos autores apontam que o cenário atual favorece aos professores a exploração de um leque de recursos digitais, tais como animações e simulações, que podem contribuir para a experimentação executada em meios virtuais (SENA DOS SANTOS, 2008; SILVA et al, 2016).

Visando a desenvolver uma formação ofertada a partir das necessidades dos licenciandos, consideramos importante ouvi-los, a fim de evitar iniciativas verticalizadas. Isso pode facilitar o desenvolvimento de um processo formativo que promova uma efetiva construção e integração de diferentes dimensões de conhecimentos (ROSA et al, 2017). Essa pesquisa nos auxilia a compreender as percepções dos licenciandos sobre tópicos considerados fundamentais para uma formação continuada que integre tecnologia, para apoiá-los no processo de formação do TPACK.

Portanto, o objetivo deste artigo é analisar as percepções de licenciandos de Física sobre aspectos tecnológicos, pedagógicos e de conteúdo inerentes à prática profissional do professor de física. Os resultados obtidos com este estudo poderão indicar caminhos e questões a serem problematizadas no desenho de estratégias formativas, de maneira a auxiliar os futuros professores a integrar os diferentes conhecimentos, formando o TPACK. 


\section{REFERENCIAL TEÓRICO}

A literatura sobre a formação de professores aponta para a necessidade de um desenvolvimento docente marcado pela reflexão sobre a prática profissional e sobre as condições dos contextos educativos (SCHÖN, 2000; ZEICHNER, 2008). Por meio de termos como professor reflexivo ou professor pesquisador, estes autores defendem que a construção da identidade e da autonomia profissional docente é marcada pelas práticas pedagógicas e pela sua experiência no contexto escolar, as quais permitem que o professor construa seus saberes e conhecimentos por meio de um processo de ação e reflexão constantes.

Para tratar sobre formação docente, é imprescindível levar em conta os saberes docentes e a realidade do contexto escolar em que o professor atua (BACCON, ARRUDA, 2010). Esses saberes devem perpassar diferentes bases de conhecimento, não somente os de conteúdo, demandando das iniciativas de formação estratégias para preparar os futuros professores para ensinar com base na integração entre diferentes saberes (NIESS, 2005).

Pesquisas sobre formação de professores revelam que, sem dominar o conteúdo a ser ensinado, o professor não pode exercer de forma adequada sua função profissional (CARVALHO, GIL-PEREZ, 2011). Entretanto, este não pode ser desvinculado do conhecimento pedagógico e, de acordo com Carvalho e Sasseron (2018, p.43), “[...] inegavelmente o professor precisa saber o conteúdo que vai ensinar, mas precisa saber também como vai ensinar para os alunos aprenderem". O professor precisa conhecer estratégias pedagógicas capazes de ajudá-lo no processo de ensino-aprendizagem de determinado conteúdo.

No ensino de física, especificamente, essas estratégias pedagógicas possuem especial importância, pois diversos conceitos e definições dessa área do conhecimento possuem alto grau de abstração. Além disso, muitas vezes, os alunos precisam lidar 
com objetos e materiais que se encontram fora do contexto humano de apropriação como, por exemplo, os conceitos apresentados em escala subatômica (cuja visualização é impossível) no âmbito da física moderna e contemporânea (SENA DOS ANJOS, 2008).

Além disso, as tecnologias digitais, assim como a Física, permeiam as vidas de professores e alunos (MOREIRA, 2018) e, devido à sua presença no cotidiano, alguns autores defendem sua integração aos espaços escolares, contextualizando com a realidade vivida pelos discentes e com abordagens interdisciplinares (TEIXEIRA, 2014).

Para que essa integração seja adequada às necessidades educativas dos alunos e dos contextos, as escolhas pedagógicas dos professores com o uso de tecnologias devem ser feitas de maneira reflexiva, articulando conhecimentos pedagógicos e de conteúdo. Nessa perspectiva, uma formação criativa de professores de física valoriza o diálogo entre TDIC, conhecimento sobre o processo de construção da ciência, sobre a física e sobre estratégias pedagógicas que ajudem no processo de ensinoaprendizagem. O conhecimento tecnológico pedagógico de conteúdo (TPACK) é um quadro teórico que pode facilitar a busca pela articulação entre os diferentes conhecimentos do professor e a escolha de estratégias educativas mais adequadas para diferentes objetivos de ensino (ESPÍNDOLA, 2010).

O TPACK é um quadro teórico implementado por Mishra e Koehler (2006) baseado na abordagem de Shulman (1986) do PCK. O PCK, de acordo com Shulman (1987), é a interseção entre conhecimento pedagógico e de conteúdo, ou seja, é a capacidade de um professor transformar seu conhecimento do conteúdo com relação às necessidades e estilos de aprendizagem dos estudantes, levando em conta suas experiências. Esse conhecimento distingue um especialista no conteúdo de um bom professor desse conteúdo. No campo da Física, por exemplo, ele ajudava distinguir um especialista em Física de um profissional que consegue ensinar os conteúdos desta 
área, de forma clara e objetiva, utilizando diferentes metodologias e estratégias pedagógicas, de maneira situada às problemáticas de ensino-aprendizagem.

Mishra e Koehler (2006) acrescentam o conhecimento tecnológico como componente necessário à formação do professor, formando a abordagem do TPACK. Este é apontado como uma forma de pensar o conhecimento que apoia os professores na integração da tecnologia ao ensino, de maneira situada, ou seja, visando a atender a objetivos de ensino específicos (MISHRA e KOEHLER, 2008). Vários autores chamam a atenção para a necessidade de articulação dos conhecimentos pedagógicos do conteúdo aos contextos de integração das TDIC (NIESS, 2005; VOOGT; MCKENNEY, 2017).

Com base nessas discussões, Mishra e Koehler (2006) conceituam os diferentes tipos de conhecimentos: 1) Conhecimento do conteúdo (CK), que se refere ao assunto a ser ensinado ou aprendido; 2) Conhecimento Pedagógico (PK), que engloba processos e práticas ou métodos de ensino e aprendizagem, incluindo propósitos educacionais, valores e objetivos gerais e; 3) Conhecimento Tecnológico (TK), que é o conhecimento sobre ferramentas tecnológicas, tais como livros, pincel e quadro branco, e tecnologias digitais.

Com relação à pedagogia e aos conhecimentos pedagógicos, existem diferentes perspectivas sobre o processo de ensino-aprendizagem e diferentes formas de mobilizar tais conhecimentos, uma delas é a abordagem tradicional e uma outra conhecida nos contextos escolares é a construtivista, em que o aluno passa a ser o principal agente no processo de construção do conhecimento (REZENDE, 2000).

O conhecimento de física também pode ser abordado por diferentes perspectivas, visto que, além dos conteúdos trabalhados de forma usual (como, por exemplo, fórmulas para aplicação em fenômenos físicos), conteúdos como história da 
ciência/física e física moderna e contemporânea podem estar presentes no contexto escolar da educação básica (MARTINS et al, 2015).

A física carrega um alto grau de abstração no entendimento de vários conceitos e definições, além de lidar com materiais e objetos que estão fora do contexto de apropriação do ser humano (SENA DOS ANJOS, 2008; ARAUJO; VEIT, 2011; HEIDEMANN et al, 2012). Nessa perspectiva, os recursos computacionais, em particular, as simulações, podem contribuir substancialmente para facilitar o ensino e a aprendizagem em Física (SENA DOS ANJOS, 2008).

O TPACK compreende o conhecimento de estratégias e representações para o ensino de conteúdos específicos com a integração das TDIC, o conhecimento dos currículos e materiais curriculares para integrar a tecnologia no ensino dos conteúdos e o conhecimento sobre como as TDIC podem ajudar os alunos na aprendizagem de determinado conteúdo (MISHRA; KOEHLER, 2006; NIESS, 2005).

\section{Percurso Metodológico}

\subsection{Procedimentos de Coleta e ANálise de Dados}

Trata-se de uma pesquisa de natureza qualitativa cujos dados foram coletados a partir da realização de entrevistas semi-estruturadas com 12 alunos de uma turma do último ano do curso de licenciatura em física do Instituto Federal do Espírito Santo (Ifes), no período anterior ao início do estágio curricular obrigatório nas escolas.

O curso de licenciatura, no qual foi realizada a investigação, é ofertado anualmente, de forma presencial, durante o turno integral e possui duração de 3,5 anos. As disciplinas pedagógicas são distribuídas ao longo de todo o curso, com uma ou duas disciplinas nos períodos iniciais e três ou quatro nos últimos semestres. As disciplinas de estágio supervisionado são realizadas nos últimos três semestres do curso, sendo o estágio 1 no quinto, o 2 no sexto e o 3 no sétimo semestre. 
O roteiro que orientou a realização das entrevistas possuía questões voltadas para: a) as percepções dos licenciandos sobre a profissão docente e o papel do professor na aprendizagem dos alunos; b) sobre o ensino de física nas escolas, além das visões sobre a ciência em si, que podem influenciar a forma como eles percebem a formação docente; e c) sobre as tecnologias digitais de informação e comunicação e sua integração na educação e no ensino de física.

As entrevistas realizadas foram gravadas e transcritas ${ }^{1}$, com autorização dos sujeitos e analisadas segundo a abordagem da análise temática de conteúdo (BARDIN, 2016). Esta consiste em um conjunto de técnicas sistemáticas de análise que permitem inferir conhecimentos relacionados ao conteúdo das mensagens. Para isso, divide-se em: pré-análise, exploração do material e tratamento dos resultados, além de inferência e interpretação.

As categorias para análise das entrevistas com os alunos foram estabelecidas $a$ posteriori, e agrupadas em tópicos de acordo com os objetivos da entrevista.

\section{RESULTADOS E DISCUSSÃO}

Os resultados das entrevistas aplicadas aos participantes da pesquisa foram analisados de acordo com suas percepções sobre os aspectos pedagógicos, de conteúdo e tecnológicos. Considerando-se que os diferentes conhecimentos são intrínsecos e aparecem em conjunto na prática docente, os aspectos relacionados (pedagogia, conteúdo e tecnologia) também são articulados, na percepção dos licenciandos, portanto, essa separação não é absoluta. Entretanto, cada grupo de categoria reflete percepções gerais dos sujeitos, quando estavam discutindo sobre questões específicas, situadas no âmbito de uma abordagem conceitual integrada -

\footnotetext{
${ }^{1}$ As últimas quatro entrevistas foram realizadas por telefone, devido à pandemia SARS-COV-2, que causa a Covid-19, em função da qual as instituições de ensino do país tiveram seus funcionamentos interrompidos. 
integração de tecnologias no ensino de física -, o que apoia a compreensão de como essas articulações foram articuladas espontaneamente por eles.

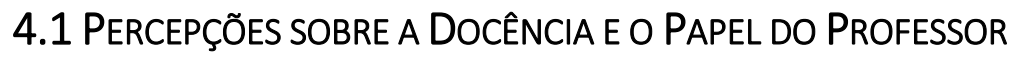

Os licenciandos foram indagados sobre seu interesse pela licenciatura e pela profissão docente, ao quê, sete deles responderam que não tiveram a licenciatura como primeira opção de curso, ou seja, pretendiam cursar o bacharelado ou curso de alguma outra área, como a engenharia.

A falta de interesse pelo magistério decorre dos desafios enfrentados pela profissão, como falta de estrutura física das escolas, baixa remuneração, desvalorização da profissão docente pela sociedade de forma geral. Além desses pontos, Castro e Queiroz (2007) destacam que existe um grande desinteresse, por parte dos estudantes da educação básica, pela ciência e especificamente pela Física, o que se torna um grande obstáculo para esses futuros professores, promovendo uma desmotivação pela docência.

Quando os licenciandos refletiram sobre o que é ser um bom professor, houve uma resposta majoritária sobre ter habilidades para a transmissão de conteúdo. Entre os entrevistados, dez deles enfatizaram essas habilidades, destacando a importância do conteúdo (Quadro 1).

Quadro 1: Trechos transcritos dos relatos do licenciando L8.

É aquele professor que consegue passar de forma clara o que ele tem pra passar, que ele consegue explicar o conteúdo com clareza e o aluno consegue entender. (L8)

Esta ênfase na transmissão de conteúdo é discutida por Tagliati et al (2018) ao indicarem que as disciplinas de conteúdos específicos estão melhor articuladas nas estruturas curriculares em relação às disciplinas pedagógicas. Segundo os autores, isto 
demarca uma tendência de maior valorização dessas disciplinas de conteúdo específico.

Outros dois alunos destacaram, também, a importância da definição de estratégias didáticas para abordar esse conteúdo, mostrando uma valorização maior dos conhecimentos pedagógicos (Quadro 2).

Quadro 2: Trechos do relato do licenciando L11.

Primeiro que para ser um bom professor eu acredito que tem que ter basicamente duas coisas. Que é um conhecimento aprofundado de conteúdo, saber o que ele está ensinando, ter um conhecimento amplo né, e segundo, ter um conhecimento amplo das práticas pedagógicas. Não só saber o conteúdo e sim como ele vai passar esse conteúdo. (L11)

Observamos, no relato desse licenciando, uma percepção da importância da integração entre o conhecimento do conteúdo que será ensinado com o conhecimento pedagógico, articulação fundamental para superar a concepção ingênua na qual o professor não precisa ter uma formação acadêmica, bastando ter domínio do conteúdo e bom senso (WARDENSKI et al, 2019).

Entre esses dez alunos, três destacaram, ainda, que o professor deve agir como um mediador em de sala de aula, ou seja, deve procurar facilitar o processo de ensinoaprendizagem por meio de metodologias, comunicação e tecnologia. Neste caso, destacamos o uso de recursos tecnológicos sendo citado pela primeira vez como um conhecimento necessário à docência.

Quadro 3: Trechos do relato do licenciando L9.

Tem o conhecimento do conteúdo, tem essa forma de como saber se comunicar com o aluno, aí nisso eu também engloba as teorias de aprendizagem... um pouco de oratória também, eu acho que é muito importante. E alguns casos o conhecimento da tecnologia (L9).

No relato de L9 (Quadro 3), o participante defende que o professor tenha um conjunto de conhecimentos, relacionados principalmente com aspectos pedagógicos 
e tecnológicos. Podemos perceber, nesse sentido, como a importância da diversidade de conhecimentos, um requisito prévio para a formação do TPACK, começa a emergir na fala de alguns licenciandos.

Além disso, alguns participantes da pesquisa citaram aspectos mais abstratos sobre as características que eles consideram necessárias para a prática de um professor, como ter domínio de turma e habilidades para estimular a aprendizagem dos alunos. Esse tipo de habilidade foi citada por sete deles e pode ser constatada no relato de L6 e L8, a seguir (Quadro 4):

\section{Quadro 4: Trechos das falas dos licenciandos L6 e L8.}

Então, eu acho que ser um bom professor é aquele que vai atender a demanda de vários alunos diferentes, cada aluno vai querer aprender de uma forma diferente. Pra ser um bom professor você vai ter que atrair o que o aluno quer, tem que dar o aluno quer para ele querer aprender e isso pra mim seria ser um bom professor. (L6)

Ah, eu acho que a forma como ele lida com a turma, questão de ele saber conversar, saber lidar com as situações problemas que são colocadas... esse tipo de característica, né. (L8)

Esses aspectos mais gerais e, por vezes, abstratos, citados pelos licenciandos, representam, segundo Cardoso et al (2012), visões do senso comum que levam a prática do professor a um status profissional limitado e simplificam a sua complexidade. Isso, porque estão mais relacionados com habilidades instintivas do que com saberes específicos que podem ser adquiridos ao longo da formação e do exercício profissional docente. Esses conhecimentos são, para os autores, as bases essenciais para a constituição do professor e devem ser trabalhados a fim de serem mobilizados durante a prática.

Ao perguntar se eles julgavam que a docência poderia ser aprendida, houve uma unanimidade concordando que sim. Entretanto, dez licenciandos se restringiram a mencionar o aprendizado através da prática (Quadro 5). 
Quadro 5: Trechos dos relatos dos licenciandos L8 e L9.

Sim, com certeza. Eu acho que à medida que você vai adquirindo experiência, você vai melhorando. Isso não só na docência, mas em qualquer outro campo (L9)

Acho que na prática. Acho que o professor, ele consegue ir aprendendo a lidar com as turmas. Por exemplo, a licenciatura não vai te ensinar a dar aula, mas acho que a prática vai te ensinando e você vai melhorando. Vai ver que ele ta errando em certos aspectos e vai melhorando. (L8)

Isto foi reforçado quando perguntados sobre o que eles acreditam que poderia ser melhorado no curso de licenciatura, ao quê, seis indivíduos alegaram que o curso poderia ter mais práticas pedagógicas (Quadro 6).

Quadro 6: Trechos do relato do licenciando L8.

Eu acho que é um curso que traz muita riqueza, é muito amplo, tem muita coisa pra aprender. A gente já aprende aqui o básico, a gente aprende aonde procurar certas coisas, mas como licenciatura eu acho que fica devendo um pouco. A gente aprende muitas matérias, mas a gente não coloca a mão na massa. Eu tive muita dificuldade quando entrei na sala de aula, vi muitas coisas, muita matéria pedagógica, muita matéria de física, mas na hora de atuar mesmo eu senti dificuldade porque nada prepara a gente pra isso. (L8)

Além disso, um aluno relatou que o que mais vai ajudá-lo, na sua profissão, serão as intervenções de estágio, porque dão ênfase à prática (Quadro 7).

Quadro 7: Trechos do relato do licenciando L9.

Eu acho que as que mais me ajudariam como docente seriam as intervenções de estágio porque é nelas que a gente realmente vive a sala de aula (L9).

Como apontado em diversos trabalhos na literatura, muitas vezes os professores em formação, quando pensam sobre a constituição do docente, dão um destaque para a prática (MEDEIROS; CABRAL, 2006). Isso não significa que eles não compreendam a importância dos conhecimentos e das reflexões teóricas, mas que a priori elas não são levadas em consideração em seus relatos, demonstrando uma valorização maior da prática, como se essa fosse suficiente para trabalho pedagógico. De acordo com Medeiros e Cabral (2006), a prática, por si mesma, não é capaz de se modificar, assim 
como a atividade teórica não leva à transformação da realidade, não se objetiva e não se materializa, razão pela qual, a percepção manifestada pelos licenciandos configurase como um desafio para a formação de professores.

Enquanto isso, três licenciandos reconhecem e destacam outras formas de aprendizagem para além da prática. L10, por exemplo, na medida em que defendia que as habilidades necessárias para ser professor podem ser aprimoradas, tratou sobre a importância de uma formação continuada para que um indivíduo possa aprender a ser professor. Entretanto, o licenciando não definiu como essa formação poderia ser organizada (Quadro 8).

\section{Quadro 8: Trecho do relato do licenciando L10.}

Acredito que existam pessoas que podem nascer já com essa facilidade, mas também acredito que isso também pode ser aprimorado, né, mas também aprendido ao decorrer da nossa vida, da nossa carreira. Acredito que isso possa ser melhorado com formações que não sejam formações únicas e exclusivas, mas formações continuadas. (L10)

Por outro lado, nove desses licenciandos, ao pensarem na formação que vivenciavam no curso de licenciatura, destacaram o papel das leituras de textos e discussões realizadas durante as disciplinas pedagógicas, explicitando a importância do aporte teórico. Embora essas respostas possam parecer contraditórias, os resultados mostram como, por meio da reflexão promovida na própria entrevista, os licenciandos repensaram determinadas opiniões prévias e consideraram a relevância de outros aspectos para a formação docente.

Um exemplo é a reflexão de L7 (Quadro 9), que atuava como professor antes de fazer a licenciatura e destacou a falta que um aporte teórico fez em sua prática.

\section{Quadro 9: Trecho do relato do licenciando L7.}

Eu vou falar de mim quando eu dava aula lá, assim, eu me arrependi hoje depois de ter entrado num curso de física porque eu vi que eu falei muita besteira. Tipo... eu trabalhei, foi bom, mas também foi ruim porque eu era muito novo na época e eu fiz algumas coisas erradas. Hoje eu sei que fiz errado e 
eu acho que não tava na hora ainda e acho que deixar pra aprender na prática estraga algumas turmas ou alunos pra depois você conseguir, digamos assim, fazer as coisas certas (L7).

A partir desse momento, percebemos o surgimento da noção de teoria, o que nos remete à definição dada por Silva (2011), qual seja um marco que estrutura e funciona como base para várias atividades. Estas teorias dizem respeito tanto às produções científicas resultantes da reflexão teórica das ciências sociais, como psicologia e sociologia, quanto às formulações pessoais dos professores. Elas influenciam as concepções, ideias e expectativas que os professores constroem a respeito da ação de ensinar, impactando, também, a própria prática (SILVA, 2011).

\subsection{PercepÇões Sobre a Física, Seu Ensino nas Escolas e o Papel do Professor de Física}

Ao serem questionados sobre o que é ciência, a maior parte dos licenciandos, como esperado, teve dificuldade em articular suas respostas, tendo em vista a complexidade desta definição. A intenção desta pergunta era compreender a percepção de ciência, tendo em vista que essas podem impactar a prática educativa. Ao responderem, três deles se basearam no método científico, como podemos observar no excerto abaixo (Quadro 10):

Quadro 10: Trecho do relato do licenciando L6.

Ciência pra mim é aquilo que vai seguir a metodologia científica. Uma forma de fazer perguntas certas, que você consiga experimentar e a partir dessas perguntas quando você tem um corpo muito grande de perguntas respondidas e um corpo muito grande de testes que dê uma confiabilidade em algo, montar uma teoria científica que generalize aquilo que possa continuar sendo testado sucessivamente, e faça previsões sucessivamente. (L6)

Quando se trata de percepções de professores em formação, Pieroni et al (2017) afirmam que é comum existir uma visão de ciência neutra, dogmática e infalível. Em geral, a descrição detalhada do método científico como um conjunto de etapas prédefinidas, quando desacompanhada de reflexão sobre a natureza da ciência, reflete 
uma confiança exacerbada na ciência como um meio para solucionar qualquer tipo de problema. Este tipo de visão impacta a prática de professores de ciências e eles tendem a adotar modelos de ensino baseados na transmissão das verdades científicas (PIERONI et al, 2017).

Ao refletir sobre como os professores podem abordar os conteúdos científicos, três licenciandos apontaram que é necessário variar as formas de exposição de conteúdos, podendo utilizar, também, a história da ciência/física, apresentando um pensamento diferente do exposto no parágrafo anterior. No total, três dos licenciandos acreditam que devem abordar a história da ciência/física em sala de aula, como podemos observar no relato de L4 (Quadro 11).

Quadro 11: Trecho do relato do licenciando L4.

Eu vejo diferenças em como os meus professores abordaram no bacharelado na ufes e na licenciatura no ifes. No bacharelado foi muito matemático, foi muito saber fazer as partes matemáticas da física e faltou um pouco da história da ciência. (L4)

Sobre "o que é ser um bom professor de física", as respostas foram diferentes das respostas da pergunta "o que é ser um bom professor", pois aqui eles conseguiram concretizar as particularidades da disciplina. Neste sentido, os licenciandos citaram a importância de relacionar a disciplina ao cotidiano do aluno, destacando, também, a relevância da interdisciplinaridade. Essa relação do conteúdo vinculada ao cotidiano contribui para que o aluno perceba a importância da física, permitindo um diálogo dessa disciplina com o mundo (TEIXEIRA, 2014). Entretanto, podemos observar, pelo excerto abaixo, que não fica claro o que seria essa relação com o cotidiano, que é citado de forma genérica (Quadro 12).

Quadro 12: Trecho do relato do licenciando L11.

Acredito que um bom professor de física, é um professor também, claro né, ter um conhecimento mais aprofundado do conteúdo e que tenha também conhecimento de ....interdisciplinaridade. Ele fala sobre a física, mas não só sobre a física, mas a física aplicada no dia a dia, na realidade, no cotidiano do aluno. (L11) 
Um licenciando julga que um bom professor de física é aquele que consegue ensinar a disciplina de maneira a facilitar a compreensão pelos alunos, tendo em vista que muitos conteúdos são complexos (Quadro 13).

Quadro 13: Trecho do relato do licenciando L6.

De física eu acho que é um pouco mais complicado, porque você teria que evitar na física alguns pontos que são meio que complexos para o dia a dia das pessoas né, a maior parte das pessoas não vai querer usar matemática no seu dia a dia, não vai querer ser engenheiro, não vai querer ser cientista, etc, então você ensinar física evitando esses pontos você iria alcançar um público maior, mas eu acho extremamente difícil. (L6)

Esse licenciando acredita que o professor de física deveria procurar meios de abordar o conteúdo de maneira mais conceitual, evitando uma matematização muitas vezes usada em demasia, seja na educação básica, seja no ensino superior, o que é reforçado na literatura por alguns pesquisadores (MOREIRA, 2018).

Outro relato que merece destaque é o de $L 7$, afirmando que, para ser um bom professor de física, o profissional precisa ter formação específica em licenciatura, ou seja, formação pedagógica. Esse relato exemplifica que existem profissionais de outras áreas lecionando física, indicando um déficit de profissionais nesta área no mercado, fato também apontado por Borges (2006) (Quadro 14).

Quadro 14: Trechos do relato do licenciando L7.

Ai é a formação, a gente tem muito profissional bom, mas tem muito profissional ruim também. Aí já entra na parte mais de formação. Às vezes você tem uma situação onde um cara fez geologia, que é o caso de uma pessoa que eu conheço, o cara é geólogo, fala que é engenheiro e tá dando aula de física. Ele não tem a formação específica. Eu, particularmente, não concordo muito com isso, mas é o que a gente mais vê, né?. (L7)

\subsection{Percepções sobre TeCnologia na Educação e no Ensino de Físıca.}

Quando perguntados sobre o que é tecnologia, apenas três licenciandos procuraram apresentar uma definição. Dois responderam ser "ferramentas" que 
facilitam o aprendizado e um a definiu como um conjunto de técnicas para se adquirir algo (Quadro 15).

Quadro 15: Trechos dos relatos dos licenciandos L2 e L4.

Tecnologia eu entendo que seja uma ferramenta para poder facilitar o aprendizado. Você pode ter simulações, aplicativos de celular que fazem análise em seu sistema também. Bem mais para facilitar o conhecimento. Aprender mais. E creio que estejamos numa era moderna. Tipo, se você for usar um celular, todo mundo vai ter um celular no bolso. (L2)

Então a palavra tecnologia em si é meio que uma aplicação do conhecimento científico pra facilitar a vida do ser humano, claro que nem sempre facilita mas acho que a ideia seria essa, você ter uma facilidade, ter uma coisa desde que as primeiras tecnologias você tem uma melhoria na sua qualidade de vida, uma facilidade pra você fazer funções que geralmente não seria tão fácil e é uma aplicação do conhecimento científico direta né, você produz conhecimento e a tecnologia é diretamente aplicação desse conhecimento, é mais rápida. (L4)

O licenciando L4 traz uma visão muito comum da tecnologia, como aplicação direta do conhecimento científico, a qual, de certa forma, se aproxima da perspectiva de ferramenta apontada por L2, ao tratá-la como algo externo ao ser humano, um produto que lhe serve como facilitador.

Essa visão de tecnologia como 'ferramenta' ou como 'técnica' é apontada na literatura e Lima et al (2012) discutem que tais termos são frequentemente usados por professores em formação quando procuram definir os recursos tecnológicos, trazendo a ideia de praticidade, de algo que auxilia e/ou facilita atividades humanas, sem uma necessária reflexão de que são, também, produções humanas. Isso exemplifica o que, de acordo com Giannella (2007), constitui uma visão instrumental de tecnologia, cujos recursos são tidos como ferramentas neutras e não trazem conteúdos de valor intrínseco. Segundo essa abordagem, nos contextos educativos, as TDIC são integradas como ferramentas didático-pedagógicas prontas, levando necessariamente à eficiência do processo educativo. 
Outros licenciandos tiveram dificuldade em definir tecnologia e apontaram exemplos de recursos utilizados no cotidiano. Já pensando no contexto educacional, três citam os principais simuladores utilizados no ensino de física (Quadro 16).

Quadro 16: Trecho do relato do licenciando L12.

Ah, tecnologia é tudo que nós podemos... como posso dizer... fazer no computador, simular um acontecimento físico, temos o Phet Colorado ${ }^{2}$ que tem várias simulações de etapas de física, como cinemática, elétrica, ai podemos usar isso para dinamizar a aula, o que torna bem interessante. (L12)

Apesar da dificuldade na definição de tecnologia, ao perguntar o que eles julgavam sobre seu uso na educação, todos defenderam sua integração, acreditando que isso possa melhorar o processo de ensino-aprendizagem.

Sobre a tecnologia no ensino de física, oito licenciandos acreditavam que as tecnologias auxiliam na demonstração e na simulação de efeitos físicos, aproximando assim a física ao cotidiano do aluno, questão também abordada anteriormente na pergunta "o que é ser um bom professor de física". Esse ponto é reforçado por pesquisadores em ensino de física, ao observarem um grande crescimento e avanço no desenvolvimento das simulações, na esperança de que os alunos possam desenvolver seus aprendizados em física, seguindo seus ritmos individuais (SENA DOS ANJOS, 2008) (Quadro 17).

Quadro 17: Trechos dos relatos dos licenciandos L11 e L1.

Tecnologia no ensino da física eu acho ela muito válida porque tem muitos assuntos, por exemplo, um assunto simples pra gente que é velocidade relativa, movimento relativo, muitas vezes para o aluno aquilo é complicado então que você usa software, usa vídeos, gifs, para mostrar, por exemplo algum movimento relativo fica mais lúdico para o aluno, então fica mais palpável para ele. Então eu acho bastante válido em vários sentidos, esse é um exemplo. (L11)

Porque tem muitas coisas que a tecnologia facilita na própria demonstração. O que a gente aprendeu em TIE, tem vários sensores e coisas que dá para gente mostrar, medir o campo magnético na hora,

\footnotetext{
${ }^{2} \mathrm{O}$ phet colorado citado pelos licenciandos é um site resultante do projeto PhET Simulações Interativas da Universidade de Colorado Boulder, que cria simulações interativas gratuitas de matemática e ciências. Têm grande utilização no ensino de física por serem de fácil manuseio, simples e poderem ser executadas online ou mesmo baixadas para posterior utilização. Disponível em: https://phet.colorado.edu/pt_BR/.
} 
ali, para o aluno saber que aquilo existe, não há apenas uma conta, um número, eu acho essencial também (L1).

Entretanto, três licenciandos afirmaram que as tecnologias não são integradas, seja por falta de conhecimento do docente ou por não ser acessível aos alunos de rede pública. Além disso, três deles defenderam que as estratégias de integração tecnológica precisam ser repensadas (Quadro 18).

\section{Quadro 18: Trecho do relato do licenciando L9.}

Eu acho que pode ajudar muito se for bem utilizada. Existem casos onde, às vezes por falta de conhecimento do docente, as TDIC acabam atrapalhando mais do que ajudando. Então as vezes isso pode acontecer...por exemplo, uma simulação do phet. Às vezes a simulação do phet ela reflete um cenário específico. E muitas vezes o professor acaba ignorando esse fato, então o aluno quando ele vê a simulação, ele pensa "não, isso vai acontecer sempre", mas não, aquilo é um caso específico. Então esse caso eu não teria medo, né, de afirmar que foi uma subutilização da metodologia. (L9)

A necessidade de repensar a utilização pedagógica das TDIC também é apontada por Lima et al (2012), para quem, muitas vezes, o professor utiliza recursos a fim de apoiar metodologias de ensino tradicionais. Neste sentido, uma estratégia evidente é a apresentação de conteúdos por meio de videoaulas. Ou seja, as tecnologias possuem o papel de apoiar um ensino instrucionista, no qual o aluno assiste às apresentações do professor, ou ao vídeo, e recebe as informações de forma passiva. Embora os licenciandos tenham problematizado a forma como a integração de TDIC muitas vezes é feita, eles não conseguiram pensar em propostas diferentes.

Esse resultado pode estar relacionado com suas experiências como alunos. Dez licenciandos afirmaram, por exemplo, não ter vivenciado nenhuma atividade pedagógica baseada na integração de TDIC no ensino básico, enquanto dois citaram iniciativas de transferência de conteúdos, ou seja, também atividades pedagógicas instrucionistas (Quadro 19). 
Quadro 19: Trecho do relato do licenciando $\mathrm{L} 2$.

Tinha, a escola disponibilizou. Tablet. (...) A gente também tinha um sistema de captura de imagens. O professor ligava o slide e você escrevia esse código no tablet e você capturava o que passava no slide no seu próprio tablet, você não precisava tirar foto (L2).

No que diz respeito ao ensino superior, por outro lado, todos os licenciandos relataram ter utilizado TDIC, como simuladores, na disciplina de TIE. Tal disciplina, denominada Tecnologias Integradas à Educação, é obrigatória na licenciatura em física e tem como objetivo principal utilizar ferramentas tecnológicas no ensino da disciplina em favor da construção do conhecimento e apresenta softwares, aplicativos de celular, ambientes virtuais, tecnologias aplicadas à Educação a distância e integração de mídias (Quadro 20).

Quadro 20: Trecho do relato do licenciando L9.

Bom, a primeira vez que usei uma TIC foi numa disciplina de TIE foi uma atividade que o professor tinha passado, onde nós tínhamos que elaborar um roteiro de uma atividade da metodologia POE eu usei o próprio phet colorado. Depois disso eu fiz uma tentativa, não deu muito certo, de aplicar o Peer Instruction, e aí foi na minha intervenção em estágio I no Maria Ortiz (L9).

Cinco deles também disseram que utilizaram tecnologias nas suas disciplinas de estágio supervisionado (os mesmos simuladores), ou seja, as tecnologias vivenciadas na disciplina de TIE estão sendo levadas por eles mesmos para o ensino básico através dos estágios supervisionados, mas ainda com muita dificuldade e sem saber como integrá-las.

Esse resultado mostrou que a integração de TDIC no ensino é uma atividade complexa, como destacado por pesquisadores, ao salientarem que a simples presença de recursos tecnológicos nas escolas não garante bons resultados (ALMEIDA, SILVA, 2011), sendo necessária uma abordagem como o TPACK para embasar a integração das TDIC no contexto escolar. Isso é importante para que os indivíduos consigam pensar em formas situadas de integrar esses recursos, ou seja, adequadas para atingir 
objetivos de aprendizagem específicos e não se limitar a abordagens de ensino instrucionistas.

\section{CONSIDERAÇÕES FINAIS}

Este artigo analisou as percepções dos licenciandos de física que estavam vivenciando o estágio curricular obrigatório, sobre aspectos pedagógicos, de conteúdo e tecnológicos que permeiam as ações e o cotidiano de professores dessa área. Buscamos, com isso, defender que essas percepções poderiam ser problematizadas em iniciativas de formação docente, a fim de estimular os sujeitos a integrarem diferentes conhecimentos, formando o TPACK.

Com relação às percepções sobre pedagogia, percebemos que os participantes traziam ideias simplificadas sobre a profissão docente, na medida em que defendiam habilidades abstratas, vinculadas à perspectiva inata de magistério como dom natural. Isso pode estar relacionado com a pouca importância dada à teoria para o desenvolvimento profissional docente. Embora no decorrer das entrevistas parte dos licenciandos tenha apontado considerações sobre o papel, para a formação, das discussões teóricas presentes nas disciplinas pedagógicas da licenciatura, nenhum deles citou a necessária articulação teoria-prática. Iniciativas de formação de professores podem estimular os sujeitos a compreender as relações entre essas dimensões, o que facilita a construção de conhecimentos pedagógicos. Isso propicia o questionamento das concepções de senso comum dos docentes.

Entre os aspectos relacionados ao conteúdo, os licenciandos expressaram visões sobre a natureza da ciência e sobre os conteúdos de física, incluindo a forma como são normalmente abordados e como eles acreditam que isso deveria ser feito. Também, nesse momento, é importante ressaltar a importância da conexão entre a teoria e a prática, tendo em vista que o olhar do docente sobre ciência e sua produção impactam na maneira como esta é representada aos alunos. A partir da problematização sobre a 
suposta neutralidade científica, é possível haver um deslocamento do modelo vigente de transmissão/recepção de fatos, para um trabalho que leve em consideração os processos de investigação que culminam na construção de conhecimentos científicos (CARVALHO; GIL-PÉREZ, 2011). Além disso, parte dos licenciandos destacou a necessidade de abordar diferentes conceitos e conteúdos que se aproximem do cotidiano do aluno. Embora esse tipo de recomendação encontre respaldo na literatura, muitos sujeitos não conseguiram definir que tipos de métodos de ensino poderiam ser utilizados, constituindo, dessa forma, em algo a ser abordado na formação.

Com relação aos aspectos tecnológicos, foi constatada uma percepção de certa forma neutra e instrumental de tecnologia, explicitada por definições baseadas nos termos 'técnica' e 'ferramenta', como produtos prontos a serem adotados por usuários. Estas definições foram acompanhadas de dificuldade para pensar como esses recursos podem ser desenvolvidos ou apropriados pelo professor para atingir seus objetivos da aprendizagem. Essa dificuldade foi reforçada por licenciandos que afirmaram ter tentado utilizar simulações nas atividades feitas nos estágios e não terem obtido sucesso. De acordo com Peixoto (2015), a visão determinista de tecnologia pode ser superada conforme os sujeitos se engajam em dinâmicas colaborativas de integração de TDIC. Dessa forma, o trabalho em grupo e o acompanhamento constante aos licenciandos, no desenvolvimento de atividades baseadas em TDIC, visando a atingir objetivos específicos do ensino de física, pode contribuir para a superação desses desafios.

É importante destacar que a combinação de diferentes tipos de conhecimentos já aparecia nos relatos dos alunos. Entretanto, assim como as relações entre teoria e prática, os relatos não explicitavam a articulação entre pedagogia, conteúdo e tecnologia. 
Para apoiar os licenciandos na articulação entre os diferentes tipos de conhecimentos, alguns cursos de formação de professores têm se baseado no modelo do TPACK, a partir de dois tipos de abordagens, descritas por Oliveira (2017): integrativa, que busca uma compreensão das interações entre os domínios de conhecimento que compõem o TPACK e transformativa, na qual o TPACK não é compreendido como a soma dos conhecimentos individuais e, portanto, a formação deve estar centrada no desenvolvimento dos conhecimentos. Conhecer as visões dos alunos sobre estas bases de conhecimentos é um passo importante para ambas abordagens.

\section{AGRADECIMENTOS}

Agradecemos à Capes pelo financiamento parcial dessa pesquisa - código de financiamento 001. 
ALMEIDA, M.E.B.; SILVA, M.G.M. Currículo, Tecnologia e Cultura Digital: Espaços e tempos de web currículo. Revista e-curriculum, São Paulo, v.7, n.1, p. 1 - 192011.

ALMEIDA, M. E. B.; VALENTE, J. A. Políticas de Tecnologia na Educação Brasileira: Histórico, lições aprendidas e recomendações. São Paulo: Centro de Inovação para a Educação Brasileira - CIEB Estudos, 2016. Disponível em: http://www.cieb.net.br/cieb-estudos-politicas-de-tecnologia-na-educacao-brasileirahistorico-licoes-aprendidas-e-recomendacoes/.

ARAÚJO, I.S.; VEIT, E.A (2011). Uma Revisão da Literatura sobre Estudos Relativos a Tecnologias Computacionais no Ensino de Física. Revista Brasileira de Pesquisa Em Educação em Ciências, v. 4 n.3. Recuperado de https://periodicos.ufmg.br/index.php/rbpec/article/view/4069.

BACCON, A.L.P.; ARRUDA, S.M. Os saberes docentes na formação inicial do professor de física: elaborando sentidos para o estágio supervisionado. Ciência \& Educação, v.16, n.3, p.507-524, 2010.

BARDIN, Lawrence. Análise de Conteúdo. São Paulo: Edições 70, 2016.

BORGES, O. Formação inicial de professores de Física: Formar mais! Formar melhor. Revista Brasileira de Ensino de Física, v.28, n.2, p. 135-142, 2006.

CARDOSO, A. A.; DEL PINO, M. A. B; DORNELES, C. L. Os saberes profissionais dos professores na perspectiva de Tardif e Gauthier: contribuições para o campo de pesquisa sobre os saberes docentes no Brasil. In: SEMINÁRIO DE PESQUISA EM EDUCAÇÃO DA REGIÃO SUL (ANPED-SUL), 9, 2012. Anais... Caxias do Sul/RS, 2012.

CARVAlho, A. M. P., GIL-PÉREZ, D. Formação de Professor de Ciências. 10. Ed. São Paulo: Cortez, 2011.

CARVALHO, A.M.P.; SASSERON, L.H. Ensino e aprendizagem de Física no Ensino Médio e a formação de professores. Estudos Avançados, v. 32 n. 94, p.43-55, 2018.

CASTRO, G.F.; QUEIROZ, G. A formação inicial de professores de Física a partir da prática de projetos. In: VI ENPEC, 2007, Florianópolis. Atas do VI ENPEC, 2007.

ESPÍNDOLA, Marina Bazzo de. Integração de Tecnologias de Informação e Comunicação no Ensino Superior: Análise das experiências de professores das áreas de ciências e saúde com o uso da ferramenta constructore. Rio de Janeiro: UFRJ/IBqM, 2010.

GIANNELLLA, Taís Rabetti. Inovações no ensino das Ciências e da Saúde. Pesquisa e desenvolvimento da Ferramenta Constructore e do Banco Virtual de Neurociência/Rio de Janeiro, 2007, 289f; Tese (Doutorado em Química Biológica - Educação, Difusão e 
Gestão em Biociências) - Centro de Ciências da Saúde, Universidade Federal do Rio de Janeiro, 2007.

HEIDEMANN, L.A.; ARAÚJO, I.S.; VEIT, E.A. Experimentos Empíricos Versus Simulações Computacionais: Uma controvérsia no ensino de Física. In: XIV Encontro de Pesquisa em Ensino de Física, Maresias, 2012.

HEIDEMANN, L.A.; ARAÚJO, I.S.; VEIT, E.A. Experimentos Empíricos Versus Simulações Computacionais: Uma controvérsia no ensino de Física. In: XIV Encontro de Pesquisa em Ensino de Física, Maresias, 2012.

JOOGT, J.; MCKENNEY, S. (2017). TPACK in teacher education: are we preparing teachers to use technology for early literacy?, Technology, Pedagogy and Education, v. 26 n.1, p. 69-83, DOI: 10.1080/1475939X.2016.1174730. 2017.

LIMA, Luciana De; RIBEIRO, Júlio Wilson; COSTA, Mário Jorge Nunes; LOUREIRO, Robson Carlos. Reflexões sobre o Uso da Tecnologia Digital da Informação e Comunicação na Formação do Licenciando de Ciências. Anais do Workshop de Informática na Escola, [S. I.], v. 1, n. 1, 2012. DOI: 10.5753/CBIE.WIE.2012.\%P. Disponível em: http://www.br-ie.org/pub/index.php/wie/article/view/2119.

MARTINS, M. R., PALMA, G.; BOLDO, J. L. (2015). A Física Moderna e Contemporânea no Ensino Médio: Desafios e Possibilidades. In: Simpósio Nacional de Ensino de Física, XXI., Uberlândia - MG. Resumos...Uberlândia:1-8.

MEDEIROS, A.; MEDEIROS, C.F. Possibilidades e Limitações das Simulações computacionais no Ensino da Física. Revista Brasileira de Ensino de Física, vol. 24, n. 2, Junho, 2002.

MEDEIROS, M. V.,CABRAL, C. L. O. Formação docente: da teoria à prática, em uma abordagem sócio-histórica. Revista E-Curriculum. v.1 n.2 p. 1-19, 2006. Disponível em: http://revistas.pucsp.br/index.php/curriculum/article/viewFile/3122/2060.

MISHRA, P. KOEHLER, M. J. Introducing Pedagogical Content Knowledge. Annual Meeting of the American Educational Research Association. New York, 2008.

MISHRA, P.; KOEHLER, M.J. Technological pedagogical content knowledge: A framework for integrating technology in teacher knowledge. Teachers College Record, v. 108 n. 6, p. 1017-1054, 2006.

MOREIRA, M.A. Uma análise crítica do ensino de Física. Estudos Avançados, v. 32 n. 94, p. 73-80, 2018.

NAKASHIMA, R.H.R.; PICONEZ, S.C.B. Technological Pedagogical Content Knowledge (TPACK): modelo explicativo da ação docente. Revista Eletrônica de Educação, v.10, n.3, p.231-250, 2016. 
NIESS, M. L. Preparing Teachers to Teach Science and Mathematics withTechnology: Developing a Technology Pedagogical Content Knowledge. Teaching and Teacher Education, v. 21, p. 509-523, 2005.

OLIVEIRA, Maíra Marques de. Possibilidades, limites e desafios do Framework Technological Pedagogical Content Knowledge (TPACK) na Formação de Professores para Integração das TDIC na Educação Científica e Tecnológica. Dissertação de mestrado. Programa de Pós-Graduação em Educação Científica e Tecnológica da Universidade Federal de Santa Catarina. Florianópolis, 2017.

PEIXOTO, Joana. Relações entre sujeitos sociais e objetos técnicos: Uma reflexão necessária para investigar os processos educativos mediados por tecnologias. Revista Brasileira de Educação. v. 20, n. 61, p. 317-332, 2015. DOI: 10.1590/S141324782015206103.

PIERONI, Laís, G.; CRISTINA SENZI ZANCUL, Maria; VIVEIRO, Alessandra; ROSA, Aquino. Percepções De Ciência E Tecnologia de Licenciandos em Pedagogia. p. 9-11, 2017. Disponível em: http://www.santoangelo.uri.br/anais/ciecitec/2017/resumos/comunicacao/2456.pdf. REZENDE, F. As Novas Tecnologias na Prática Pedagógica sob a Perspectiva Construtivista. Ensaio - Pesquisa em Educação em Ciências. v.02, n.1, p.70-87, jan.-jun., 2000.

ROSA, L.M.R.; SUART, R.C.; MARCONDES, M.E.R. Regência e análise de uma sequência de aulas de química: contribuições para a formação inicial docente reflexiva. Ciência \& Educação, Bauru, v.23, n.1, p.51-70, 2017.

SANTOS, R.; SANTOS, E. A formação do Formador na cibercultura e suas ambiências políticas-formativas. Interfaces científicas - Educação. Aracaju, v.6, n.1, p. 35-46. out. 2017.

SCHMIDT, D.A.; BARAN, E.; THOMPSON, A.; MISHRA, P.; KOEHLER, M.J.; SHIN, T.S. Technological Pedagogical Content Knowledge (TPACK): The Development and Validation of an Assessment Instrument for Preservice Teachers. Journal of Research on Technology in Education, v.42 n.2, p. 123-149, 2009 DOI 10.1080/15391523.2009.10782544.

SCHÖN, D.A. Educando o profissional reflexivo: um novo design para o ensino e a aprendizagem. Trad. Roberto Cataldo Costa. Porto Alegre: Artes Médicas Sul, 2000.

SENA DOS ANJOS, A.J. As novas tecnologias e o uso dos recursos telemáticos na educação científica: a simulação computacional na educação em Física. Caderno Brasileiro de Ensino de Física, v.25, n.3: p. 569 - 600, dez. 2008.

SHULMAN, L.S. Knowledge and teaching: foundations of a new reform. Harvard Educational Review, v. 57, n. 1, p. 1-22, 1987. 
SHULMAN, L.S. Those who understand: knowledge growth in teaching. Educational Researcher, v. 15, n. 2, p. 4-14, 1986.

SILVA, I.P.; NUNES, E.T.; MERCADO, L.P.L. Experimentos virtuais no estágio supervisionado de Física. Caderno Brasileiro de Ensino de Física, v.33, n.3, p. 11151144, dez. 2016.

SILVA, L. N. D. Formação de professores centrada na pesquisa: a relação teoria e prática. 2011. Tese (doutorado em educação), Faculdade de educação, Universidade Federal de Goiás, Goiânia, 2011.

TAGLIATI, J.R.; NARDI, R.; CORTELA, B.S.C. Um estudo sobre os potenciais formativos de cursos de licenciatura em Física do estado de Minas Gerais. Revista brasileira de Ensino de Ciências e Tecnologia, Ponta Grossa, v.11, n.2, p.614-632, mai./ago. 2018.

TEIXEIRA, Graziela Gomes Stein. As TDIC na Formação Inicial de Professores de Física: A voz dos Egressos e Licenciandos do Curso. Dissertação de mestrado. Universidade Federal de Santa Catarina, Centro de Ciências Física e Matemáticas, Florianópolis, SC, 2014.

WARDENSKI, R. F.; SANTOS, R. F.; DUTRA, R. O.; PRADO, R. T. ; MARQUES, L.; GIANNELLA, T. R. . O professor de ciências e biologia na visão dos licenciandos: delineando desafios para a formação docente. In: Encontro Nacional de Pesquisa em Educação em Ciências (ENPEC), 2019, Natal/RN. Anais do XII Encontro Nacional de Pesquisa em Educação em Ciências, 2019. p. 1-8.

ZEICHNER, K.M. Uma análise Crítica sobre a "Reflexão" como conceito estruturante na formação docente. Educação e Sociedade, Campinas, v. 29, n. 103, p. 535-554, maio/ago. 2008. 